\title{
Erratum to: Uncertainty factor: an alternative way to express measurement uncertainty in chemical measurement
}

\author{
Michael H. Ramsey • Stephen L. R. Ellison
}

Published online: 20 March 2015

(C) Springer-Verlag Berlin Heidelberg 2015

\section{Erratum to: Accred Qual Assur}

\section{DOI 10.1007/s00769-015-1115-6}

Unfortunately, on page 2, column 1, the sentence "This would be calculated as $u_{0}=\exp \left(s_{\mathrm{G}}\right)$, where $s_{\mathrm{G}}$ is the geometric standard deviation, which is the standard deviation of the $\log _{\mathrm{e}}$-transformed distribution" was wrongly published in the original publication.

The correct sentence is "This would be calculated as $u_{0}=\exp \left(s_{\mathrm{G}}\right)$, where $s_{\mathrm{G}}$ is the standard deviation of the $\log _{\mathrm{e}}$-transformed distribution".

The online version of the original article can be found under doi:10.1007/s00769-015-1115-6.

M. H. Ramsey ( $ه)$

University of Sussex, Brighton, UK

e-mail: m.h.ramsey@sussex.ac.uk

S. L. R. Ellison

LGC, Teddington, UK 